\title{
MODEL PEMBERDAYAAN MASYARAKAT MISKIN DENGAN THE SUSTAINABLE LIVELIHOOD APPROACH BERBASIS BUDAYA LOKAL DI DAERAH LAHAN KERING NUSA PENIDA KLUNGKUNG-BALI
}

\author{
Ida Bagus Putu Mardana \\ Jurusan Fisika, Fakultas Matematika dan IImu Pengetahuan Alam \\ Universitas Pendidikan Ganesha \\ Singaraja, Indonesia \\ e-mail: idamardana@yaho.com
}

\begin{abstract}
Abstrak
Masalah kemiskinan telah menjadi perhatian serius pemerintah sekarang ini. Penanganan kemiskinan yang hanya melibatkan partisipasi keluarga miskin secara parsial, terbukti belum mampu menurunkan angka kemiskinan. Pada tahun 2012 (tahun-1) dilakukan pengkajian penanganan kemiskinan melalui pemberdayaan keluarga miskin dengan pendekatan the sustainable livelihood approach (SLA) berbasis budaya lokal. Populasi penelitian adalah seluruh keluarga miskin di 4 (empat) desa yang terpilih sebagai target penelitian, yakni desa Ped, desa Kutampi, desa Tanglad, dan desa Batukandik. Pengambilan sampel penelitian menggunakan teknik proporsive random sampling. Variabel panelitian adalah potensi wilayah dan budaya lokal, model pemberdayaan dengan SLA. Data dikumpulkan dengan pedoman survei, pedoman observasi, pencatatan dokumen dan fakta, kemudian dianalisis dengan interactive model of analysis. Hasil penelitian pada tahun 2012 menunjukkan bahwa wilayah penelitian memiliki daya dukung lahan yang cukup luas, dengan potensi pertanian-peternakan yang cukup tinggi; (2) budaya lokal masyarakat sebagian besar berakar dari nilai-nilai ajaran agama, ide/gagasan, norma dan aturan yang mewarnai aktivitas kehidupan personal dan komunal masyarakat, (3) model pemberdayaan masyarakat dengan SLA berbasis potensi budaya lokal secara sistemik terpayungi dalam kegiatan penyadaran keluarga miskin (awareness), pengkapasitasan (capacity), penguatan (strengthening), dan pelembagaan (institutionalzation), yang pengimplementasiannya dilakukan pada usaha produktif berbasis kelapa dan taniternak sapi/babi terpadu.
\end{abstract}

Kata-kata kunci: pemberdayaan, keluarga miskin, SLA, budaya lokal, lahan kering

\begin{abstract}
The poverty was the serious problem of the goverment. The poverty treatments toward them partially have no succed to decrease poornes index. In the year of 2012, it was conducted research of the poverty treatment through society empowerment by using the sustainable livelihood approach based on region potency and local culture. Population was all of poor families in four village, namely Ped, Kutampi, Tanglad, and Batukandik village. The sample of study was taken by using proporsive sampling technique. The variable of research were region potency, local sulture, and the model society empowerement. The data were collected by using survey, observaton, documentation, and then it was analyzed by using interactive models of analysis. The result of study in the first years (2012) shown that (1) the region potency of the study has a lot of land area whose a higher agriculture and animal husbandry. The local culture of society was rooted from the value of religion, ide, norma, that characterize the activity of person in society personally and communally, (2) the empowerement model of SLA based on region potency and local cultural were covered systematically in the stage of awareness, capaciting, strengthening, and institutionalization, that was
\end{abstract}


implemented in the economic production of coconout base, and agriculture-animal husbandry-integrated pilot project.

Keywords: empowerment, poverty family, SLA, local cultural, dried land area

\section{PENDAHULUAN}

Masalah kemiskinan telah menjadi perhatian serius pemerintahan sekarang ini. Jumlah penduduk miskin Indonesia, menurut data BPS tahun 2004, sekitar $17 \%$, namun garis kemiskinan yang dijadikan patokan di Indonesia dinilai sangat konservatif. Beras miskin (raskin), Bantuan Operasional Sekolah (BOS), Bantuan Langsung Tunai (BLT), Asuransi Kesehatan untuk Masyarakat Miskin (Askeskin) dan sebagainya, semua itu dimaksudkan untuk mengurangi angka kemiskinan. Ironisnya, meski berbagai program pengentasan kemiskinan dibuat, namun dampaknya sampai sekarang masih belum signifikan. Permasalah kemiskinan masih merupakan agenda serius yang dihadapi dan perlu ditanggulangi oleh Pemerintah kabupaten Klungkung, khususnya masyarakat miskin di kawasan lahan marginal dan kering desa-desa yang berada di kepulauan Nusa Penida kabupaten Klungkung-Bali. Upayaupaya penanggulangan kemiskinan dengan berbagai macam dimensinya telah banyak dilakukan, namun sangat jarang diteliti yang mengkaitkan antara kemiskinan sebuah komunitas dengan strategi komunitas masyarakat miskin untuk berjuang menghadapi tekanan proses kemiskinan. Berangkat dari preposisi tersebut, maka dipandang perlu untuk mengembangkan model pemberdayaan masyarakat dengan berbasis potensi wilayah dan budaya lokal.

Penanggulangan

masalah kemiskinan harus dipilih strategi yang dapat memperkuat peran dan posisi perekonomian rakyat dalam perekonomian nasional, sehingga terjadi perubahan struktural yang meliputi pengalokasian sumber daya, penguatan kelembagaan, pemberdayaan sumber daya manusia (Sumodiningrat, 1999). Pemberdayaan sebagai strategi pengentasan kemiskinan harus menjadi proses multidimensi dan multisegi yang memobilisasi sumberdaya dan kapasitas masyarakat (Mc Whirter, E.H.,1991; Friedman John, 1992). Salah satu pendekatan pemberdayaan masyarakat yang cukup inovatif adalah the Sustainable Livelihood Approach (SLA), yang pada dasarnya upaya pelibatan (partisipasi) masyarakat untuk belajar dan beraktivitas secara berkelanjutan dengan cara unik mereka menjalani hidup dalam rangka meningkatkan kualitas hidup mereka. Menurut Oliver Serrat (2008), the sustainable livelihood approach $(S L A)$ is the process by which rural families construct a diverse portfolio of activities and social support capabilities in their struggle for survival and in order to improve their standards of livings. Hal ini didukung oleh Shadi Hamadeh(2009), yang menyatakan bahwa "The sustainable livelihoods approach is a way of thinking about the objectives, scope, and priorities for development activities.

Di sisi yang lain, pemberdayaan komunitas secara prinsip harus memperhatikan budaya lokal masyarakat. Budaya lokal Bali pada hahikatnya dilandasi oeh nilai-nilai yang bersumber pada ajaran agama Hindhu. Masyarakat Bali juga memiliki identitas yang jelas yaitu budaya ekspresif yang termanifestasi secara konfiguratif yang mencakup nilai-nilai dasar yang dominan seperti: religius, nilai estiteka, nilai solidarittas, nilai harmoni, dan nilai keseimbangan.

Dengan pendekatan SLA (the sustainable livelihood approach), proses dan evaluasi dilaksanakan secara partisipatif. Proses partisipatif menggunakan model Dick, dimana tingkat partisipasi dibedakan menjadi tujuh, tergantung dari jenis kegiatan atau sub kegiatan yang sesuai dengan kebutuhan partisipasi yaitu pastisipasi sebagai: informan, interpreter, planner, implementor, fasilitator, researcher atau co-researcher, resipien information. 
Evaluasi program pemberdayaan masyarakat dilakukan terhadap process, outcome, dan stackholder.

Potensi wilayah merupakan modal sosial-ekonomi-politik, sumber alam (SDA) dan sumber daya manusia (SDM) suatu desa akan menjadi modal dasar program pembangunan dalam meningkatkan kesejahteraan masyarakatnya. Program pembangunan yang dicanangkan di suatu wilayah seyogyanya mengoptimalkan dan memberdayakan potensi wilayah mengacu pada kearifan lokal masyarakat setempat untuk menjaga keharmonisan dan sinkronisasi derap langkah pembangunan menuju perwujudan desa mandiri yang berakar pada potensi wilayahnya. Kearifan lokal adalah pandangan hidup dan ilmu pengetahuan serta berbagai strategi kehidupan yang berwujud aktivitas yang dilakukan oleh masyarakat lokal dalam menjawab berbagai masalah dalam pemenuhan kebutuhan mereka. Di pihak lain, kearifan lokal (local wisdom) dapat didefinisikan sebagai kebijaksanaan atau nilai-nilai luhur yang terkandung dalam kekayaan-kekayaan budaya lokal berupa tradisi, petatah-petitih dan semboyan hidup. Kearifan lokal Bali pada hakikatnya dilandasi oleh nilai-nilai yang bersumber pada ajaran agama Hindu. Masyarakat Bali mengakui adanya perbedaaan ( $r$ wa bhineda), yang sering ditentukan oleh faktor ruang (desa), waktu (kala) dan kondisi riil di lapangan (patra). Perbedaan dalam dinamika masyarakat Bali diakui karena adanya faktor desa, kala dan patra.

Masyarakat Bali sesungguhnya menjunjung tinggi nilai-nilai keseimbangan dan harmonisasi mengenai hubungan manusia dengan Tuhan (parahyangan), hubungan sesama manusia (pawongan), dan hubungan manusia dengan lingkungan (palemahan), yang tercermin dalam ajaran Tri Hita Karana. Selain nilai-nilai keseimbangan dan harmonisasi, dalam masyarakat Bali juga dikenal adanya konsep tri semaya yakni persepsi orang Bali terhadap waktu. Menurut orang Bali masa lalu (athita), masa kini (anaghata) dan masa yang akan datang (warthamana) merupakan suatu rangkaian waktu yang tidak dapat dipisahkan satu dengan lainnya. Kehidupan manusia pada saat ini ditentukan oleh hasil perbuatan di masa lalu, dan perbuatan saat ini juga menentukan kehidupan di masa yang akan datang. Dalam ajaran hukum karma phala disebutkan tentang sebabakibat dari suatu perbuatan, perbuatan yang baik akan mendapatkan hasil yang baik.

\section{METODE PENELITIAN}

Penelitian ini merupakan penelitian partisipatif (participatory research) yang menggunakan pendekatan kualitatif (qualilative research). Yang dipilih sebagai lokasi pada penelitian ini adalah 4 (empat) desa kawasan lahan marginal kering desa-desa di kepulauan Nusa Penida kabupaten Klungkung-Bali, yakni desa Ped, Kutampi, Tanglad dan Batukandik. Data dalam penelitian dikumpulkan dari informan kunci (key informan) sesuai dengan fokus penelitian, kemudian dilanjutkan mencari dan mengumpulkan data atau informasi dari para informan berikutnya dengan menggunakan teknik "snow ball sampling". Data penelitian dianalisis menggunakan model analisis interaktif (interactive model of analysis) yang dikembangkan oleh Miles dan Huberman (1992). Model analisis interaktif ini meliputi 3 (tiga) tahap, yaitu: reduksi data(data reduction); penyajian data (data display); menarik kesimpulan/verifikasi (conclusion or verification).

\section{PEMBAHASAN}

Pada tahun 2012 (tahun-1), kegiatan penelitian diawali dengan pemetaan wilayah, budaya lokal, dan karakteristik kemiskinan, yang dilanjutkan dengan analisis SWOT sebagai dasar dalam pengembangan program pemberdayaan. Potensi wilayah merupakan modal sosialekonomi-politik, sumber alam (SDA) dan sumber daya manusia (SDM) yang dimiliki suatu desa yang menjadi modal dasar (starting point) program pemberdayaan dalam meningkatkan 
kesejahteraan masyarakatnya. Program pembangunan yang dicanangkan di suatu wilayah seyogyanya mengoptimalkan dan memberdayakan potensi wilayah mengacu pada budaya lokal masyarakat setempat untuk menjaga keharmonisan dan sinkronisasi derap langkah pembangunan menuju perwujudan desa mandiri yang berakar pada potensi wilayahnya. Hasil survey, observasi dan wawancara yang mendalam dalam pendataan potensi wilayah di desa Ped, Kutampi, Tanglad dan Batukandik terungkap potensi wilayah seperti ditunjukkan pada tabel 1 .

Tabel 1. Profil Potensi Wilayah

\begin{tabular}{|l|l|c|c|c|c|}
\hline No & \multicolumn{1}{|c|}{ Potensi Wilayah } & $\begin{array}{c}\text { Desa } \\
\text { Ped }\end{array}$ & $\begin{array}{c}\text { Desa } \\
\text { Kutampi }\end{array}$ & $\begin{array}{c}\text { Desa } \\
\text { Tanglad }\end{array}$ & $\begin{array}{c}\text { Desa } \\
\text { Batu Kandik }\end{array}$ \\
\hline 1 & Luas Area(ha) & 1523 & 2500 & 1300 & 1354 \\
\hline 2 & Penduduk(or) & 6099 & 4326 & 3365 & 2097 \\
\hline 3 & KK miskin (KK) & 2.020 & 1.508 & 662 & 612 \\
\hline 4 & Kualitas SDM & 5621 & 2914 & 3519 & 2024 \\
\hline & a. SD,SMP,SMA & 238 & 37 & 13 & 12 \\
\hline & d. Sarjana & & & & \\
\hline 5 & Mata Pencaharian & 5283 & 3442 & 3372 & 2567 \\
\hline & a. Tani-ternak & 182 & 219 & 108 & 80 \\
\hline & c. PNS & 1495 & 943 & 667 & 775 \\
\hline d. Swasta & & & & \\
\hline 6 & Potensi tani & 558 & 388 & 398 & 490 \\
\hline & a. Kelapa & 46 & 78 & 18 & 100 \\
\hline b. Jagung & 78 & 100 & 105 & 56 \\
\hline c. Mangga & 314 & 56 & 234 & 78 \\
\hline e. Pisang & 219 & 233 & 231 & 226 \\
\hline f. Palawija & & & & \\
\hline 7 & Potensi ternak & 568 & 463 & 543 & 275 \\
\hline a. Sapi & 6505 & 721 & 562 & 2.500 \\
\hline b. Babi & 64 & 87 & 67 & 853 \\
\hline c. Kambing & 13.425 & 5945 & 4658 & 27.500 \\
\hline d. Ayam & & & \\
\hline & & & & \\
\hline
\end{tabular}

Berdasarkan profil potensi dan prospek wilayah 4 desa, yakni desa Ped, Kutampi, Tanglad, dan Batukandik di kecamatan Nusa Penida dapat terindentifikasi permasalahan utama yang perlu dipecahkan adalah rendahnya produktivitas ekonomi masyarakat sehingga memberi kontribusi pada rendahnya pendapatan perkapita dan pendapatan keluarga. Hal ini dapat dilihat dari ketimpangan komposisi luas lahan, jumlah penduduk terhadap komoditas produktif yang dihasilkan masyarakat. Di sisi yang lain, pemetaan, profil, ideks kemiskinan, variabel deterministik penyebab kemiskinan dari KK miskin yang dilibatkan dalam program aksi pengentasan kemiskinan melalui model pemberdayaan masyarakat dengan SLA berbasis budaya lokal di kawasan lahan kering Nusa Penida ditunjukkan pada tabel 2. 
Tabel 2. Profile Keluarga Miskin

\begin{tabular}{|l|c|c|c|c|}
\hline \multicolumn{1}{|c|}{ Profile } & $\begin{array}{c}\text { Desa } \\
\text { Ped }\end{array}$ & $\begin{array}{c}\text { Desa } \\
\text { Kutampi }\end{array}$ & $\begin{array}{c}\text { Desa } \\
\text { Tanglad }\end{array}$ & $\begin{array}{c}\text { Desa } \\
\text { Batukandik }\end{array}$ \\
\hline $\begin{array}{l}\text { Indeks Kekayaan } \\
\text { (IK) }\end{array}$ & 30,8 & 42,2 & 37,9 & 69,4 \\
\hline Lahan kering(m2) & $85 \%$ & $60 \%$ & $70 \%$ & $55 \%$ \\
\hline $\begin{array}{l}\text { Pendapatan perkapita } \\
\text { (Rp) }\end{array}$ & $<500.000$ & $<500.000$ & $<500.000$ & $<500.000$ \\
\hline Buruh & $80 \%$ & $70 \%$ & $75 \%$ & $65 \%$ \\
\hline Posisi tawar rendah & $95 \%$ & $80 \%$ & $75 \%$ & $65 \%$ \\
\hline Budaya malas & $90 \%$ & $80 \%$ & $65 \%$ & $50 \%$ \\
\hline Kesehatan rendah & $79 \%$ & $50 \%$ & $70 \%$ & $70 \%$ \\
\hline Keterbatasan sarana) & $65 \%$ & $40 \%$ & $65 \%$ & $55 \%$ \\
\hline Miskin IPTEKS & rendah & rendah & rendah & rendah \\
\hline
\end{tabular}

Hasil survey dan wawancara yang mendalam terhadap elemen masyarakat yang berada dalam garis kemiskinan menunjukkan bahwa faktor-faktor yang memberi kontribusi terhadap kemiskinan adalah rendahnya produktivitas ekonomi, karena (1) kondisi alam (lahan kering), (2) rendahnya penguasaan IPTEKS, (3) budaya masyarakat.

Hasil identifikasi terhadap kearifan lokal masyarakat di 4(empat) desa di wilayah lahan kering, di kecamatan Nusa Penida, yakni desa Ped, desa Kutampi, desa Tanglad, dan desa Batukandik seperti ditunjukkan pada tabel 3. Budaya lokal masyarakat secara substansi bersumber dalam ide/gagasan, nilai-nilai religous, norma, aturan tertulis/tak tertulis. Aktivitas dan dinamika sosial-ekonomi masyarakat, baik yang konstruktif maupun destruktif banyak diwarnai oleh kearifan lokal ini. Upaya pemberdayaan masyarakat yang melupakan budaya lokal ini tidak akan memberi hasil yang optimal, karena merupakan budaya lokal masyarakat yang dapat mempengaruhi pola cipta, rasa, dan karsa pada setiap dinamika kehidupan masyarakat.

Tabel 3. Budaya Lokal Masyarakat

\begin{tabular}{|l|l|}
\hline \multicolumn{1}{|c|}{$\begin{array}{c}\text { Produk } \\
\text { Budaya }\end{array}$} & \multicolumn{1}{|c|}{ Jenis Kearifan Lokal } \\
\hline Gagasan & $\begin{array}{l}\text { Menjual ternak saat musim kemarau, mencari pekerjaan di luar kota } \\
\text { saat musim kering datang, berhutang saat musim kering, } \\
\text { mempertaruhkan harapan hidup pada belas kasihan, dan judi, } \\
\text { menikahkan/memaksa bekerja anak dari sekolah untuk meringankan } \\
\text { beban hidup. }\end{array}$ \\
\hline Nilai-nilai & $\begin{array}{l}\text { Rwa Binedha: keyakinan akan adanya perbedaan; Tri Hita } \\
\text { Karana:keyakinan adanya tiga penyebab kesejahteraan dan } \\
\text { harmonisasi dalam kehidupan; Desa kala patra: keyakinan adanya } \\
\text { pengaruh tempat, waktu, cara dalam dinamika kehidupan, Karma } \\
\text { Phala: keyakinan akan hukum kerja yang selalu menghasilkan pahala; } \\
\text { Tri Semaya:keyakinan akan untaian waktu. }\end{array}$ \\
\hline Norma & $\begin{array}{l}\text { Tri Kaya Parisudha: wujud pikiran, perkataan dan perbuatan yang baik, } \\
\text { Tat Twam Asi: teposeliro dan toleransi dalam kehidupan beragama, } \\
\text { berkeyaninan, dan menyama-braya. }\end{array}$ \\
\hline $\begin{array}{l}\text { Aturan } \\
\text { Tertulis/Tak } \\
\text { Tertulis }\end{array}$ & $\begin{array}{l}\text { Awig-awig desa adat, yang mengatur hak, kewajiban, dan sangsi } \\
\text { dalam kehidupan bermasyarakat, Tunduk pada petuah dan perkataan } \\
\text { orang yang dituakan/ ditokohkan }\end{array}$ \\
\hline
\end{tabular}


Upaya penanggulangan kemiskinan yang paling strategis dalam era otonomi adalah memberikan peluang kepada keluarga miskin dan komunitasnya untuk mengatasi masalah mereka secara mandiri berangkat dari potensi wilayah dam budaya lokal yang dimilikinya. Ini berarti pihak luar harus mereposisi peran mereka, dari agen menjadi fasilitator pemberdayaan. Input yang berasal dari luar yang masuk dalam proses pemberdayaan harus mengacu sepenuhnya pada kebutuhan dan desain aksi yang dibuat oleh keluarga miskin itu sendiri bersama komunitasnya melalui proses dialog yang produktif agar sesuai dengan konteks potensi wilayah dan budaya lokal masyarakat setempat. Bertitik tolak dari potensi masyarakat dan budaya lokal dikembangkan model pemberdayaan masyarakat miskin di daerah lahan kering Nusa Penida. Model pemberdayaan masyarakat dengan SLA berbasis budaya lokal dapat diurai menjadi empat tahapan kegiatan pemberdayaan, yakni penyadaran, (2) pengkapasitasan, (3) pendampingan, dan (4) pelembagaan.

Model pemberdayaan masyarakat dengan the sustainable livelihood approach (SLA) berbasis budaya lokal merupakan model yang akan dikembangkan untuk meningkatkan partisipasi aktif masyarakat dalam pengentasan kemiskinan melalui pemberdayaan dan pembelajaran berkelanjutan bertolak dari potensi wilayah dan budaya lokal masyarakat setempat. Pemberian kewenangan kepada masyarakat setempat yang tidak hanya untuk menyelenggarakan proyek atau program pembangunan, tetapi juga untuk mengelola proyek tersebut akan mendorong masyarakat untuk mengerahkan segala kemampuan dan potensinya demi keberhasilan proyek/program tersebut (Mubyarto,2000).

Kemiskinan merupakan problematik yang mengakar pada kehidupan masyarat yang hidup pada kawasan marginal lahan kering. Lingkungan geografis lahan kering yang kurang menguntungkan telah membentuk dinamika sosial-ekonomi budaya masyarakat yang hanya mengandalkan rutinitas kehidupan yang bersandarkan pada daya dukung sumber alam yang sangat terbatas. Berpijak dari kenyataan ini, perlu dilakukan studi yang mendalam untuk mengupas dan merekayasa dinamisa sosial-ekonomibudaya berbasis pada budaya lokal masyarakat miskin dalam memberdayakan masyarakat untuk bisa keluar dari balutan kemiskinan yang akut. Proses transformasi berpikir, berkata dan bertindak yang tumbuh dari budaya lokal masyarakat dalam menyikapi hidup perlu dilakukan untuk dapat mengantarkan masyarakat miskin dalam berusaha dan menjalani hidup yang lebih baik dan layak.

Tahap penyadaran (awareness) merupakan tahap inisiasi untuk (1) menyadarkan KK miskin agar mampu memahami kondisi kemiskinan beserta penyebabnya, melakukan selfevaluation terhadap potensi, merefleksi terhadap permasalahan kemiskinannya dan upaya yang dapat ditempuh untuk penanggulangannya, dan memberikan penyuluhan dan pelatihan kepada keluarga miskin tentang usaha produktif dalam rangka meningkatkan taraf hidupnya. Sedangkan, pada tahap pengkapasitasan (participating) adalah tahap pelibatan partisipasi aktif dan pendampingan pada keluarga miskin untuk membangun, mengelola, dan membesarkan usaha produktifnya. Selanjutnya pada tahapan pelembagaan (institutionalization) adalah mewadahi usaha produktif KK miskin pada suatu kelompok institusi yang dapat memudahkan proses belajar, transfer IPTEKS, pemasaran, dan jaminan legalitas formal.

Dari pendekatan dialogis dan diskusi yang mendalam dengan subyek penelitian yang tersebar dalam sampel penelitian yang berada di empat desa, yakni desa Ped, Kutampi, Tanglad dan desa Batukandik, berhasil terpetakan pola dan tahapan pemberdayaan KK miskin. Hasil analisis kualitatif terhadap potensi unggul yang ada di kawasan ini, yakni kelapa dan ternak, nampaknya usaha produktif berbasis kelapa dan 
budi daya ternak sapi/babi terpadu dapat digunakan sebagai medium untuk memberdayakan KK miskin melalui pendekatan SLA, dengan mengadopsi budaya lokal masyarakat. Keterbatasan yang dimiliki lahan kering cenderung membuat kegiatan pola usaha tani bersifat subsistem (tradisional). Pola usahatani tanaman semusim yang biasanya dilakukan di lahan kering adalah pola usahatani tanaman pangan seperti jagung, kacang tanah dan jenis palawija lainnya. Pola usaha tani tanaman pangan dilakukan pada musim penghujan menggunakan teknologi sederhana dengan varietas lokal sehingga hasilnya rendah. Selain itu pemeliharaan ternak masih tradisional sehingga produktivitasnya rendah. Pemberdayaan masyarakat KK miskin di kawasan lahan kering Nusa Penida pada penelitian ini dilakukan dengan pencanangan program aksi produktif peternakan-pertanian terpadu di 4(empat) desa, yakni desa Ped, Kutampi, Tanglad dan desa Batukandik. Model pertanian-peternakan terpadu merupakan aktivitas produktif pertanian-peternakan dalam satu siklus berantai, yakni pemanfaatan limbah tanaman pada budidaya tani untuk pakan ternak. Demikian juga sebaliknya budidaya ternak, limbah ternak dapat dimanfaatkan untuk pertanian. Sebagai langkah awal diintroduksikan penanaman rumput raja dan gamal di pematang petakan lahan petani untuk menambah penyediaan hijauan pakan ternak selain itu juga diperkenalkan perkandangan menetap, dan pengawetan pakan ternak. Selanjutnya juga diintroduksikan pemanfaatan air embung untuk pertanaman sayuran (bawang merah, semangka, kacang panjang dan bawang putih) yang memiliki nilai ekonomis tinggi dengan sistem portable farming.

Program aksi usaha produktif pertanian-peternakan terpadu diawali introduksi teknologi pemanfaatan limbah tanaman untuk pakan ternak serta pemakaian limbah ternak ke pertanaman, pemeliharaan ternak secara intensif. (1) Langkah awal mengintroduksikan model perkandangan menetap dan penanaman rumput di pematang petakan lahan untuk penyediaan hijauan pakan ternak, dimana demplot taniternak terpadu dibangun meliputi: kandang koloni, reaktor biogas-biourine, pengolahan pupuk organi, dan reaktor pengawetan pakan ternak. (2) mengintroduksikan diversifikasi penanaman sumber hayati baik di pekarangan rumah, lahan tegalan kosong, dan sekitar demplot tani-ternak terpadu dan portable farming system. Setiap anggota KK miskin diminta untuk menanam dan merawat satu pohon. (3) mengintroduksi pemanfaatan embung air dalam pemenuhan kebutuhan air di musim kering. Rekayasa sosial-ekonomi dilakukan secara terpusat di tempat demplot tani-ternak yang telah dibangun di 4(empat) desa, yakni di desa Ped dan desa Batukandik, desa Kutampi dan desa Tanglad. Rekayasa sosial-ekonomi KK miskin diinisiasi dengan bantuan investasi kapital ekonomi, seperti ditunjukkan pada tabel 4. Infrastruktur fisik dan non-fisik ini merupakan mesin ekonomi yang dapat menghasilkan generate revenue bagi komunitas miskin yang bersifat harian, bulanan, dan tahunan secara berkesinambungan melalui aktivitas bertani dan beternak.

Tabel 4. Distribusi Bantuan Non-tunai

\begin{tabular}{|l|c|c|c|c|c|c|}
\hline \multirow{2}{*}{ Desa } & \multirow{2}{*}{ KK } & \multicolumn{3}{c|}{$\begin{array}{c}\text { Sapi/Babi/ } \\
\text { Ayam }\end{array}$} & $\begin{array}{c}\text { Kandang/Mesin } \\
\text { Pupuk- } \\
\text { Biogas }\end{array}$ & $\begin{array}{c}\text { Mesin } \\
\text { kelapa }\end{array}$ \\
\cline { 2 - 5 } & & S & B & A & - & - \\
\hline Ped & 20 & 1 & - & - & 1 & 1 \\
\hline Kutampi & 10 & - & 5 & 10 & - & 1 \\
\hline Tanglad & 10 & - & 5 & 10 & - & - \\
\hline Batukadik & 10 & 1 & - & 8 & 1 & \\
\hline
\end{tabular}


Hasil pemberdayaan $50 \mathrm{KK}$ miskin dalam usaha produktif ternak sapi/babi terpadu adalah (1) adanya peningkatan kompetensi dalam intensifikasi budi daya ternak sapi/babi terpadu, menuju usaha produktif yang zero waste, (2) mendorong proses transfusi IPTEKS dalam pengolahan limbah ternak sapi/babi menjadi pupuk bio-organik dan biogas, (3) adanya peningkatan investasi kelompok KK miskin dalam bentuk jumlah bibit ternak sapi/babi modal yang diberikan pada penelitian ini di masing-masing desa. Meskipun kawasan keempat desa memiliki lahan yang cukup luas, belum menjadi jaminan untuk dapat meningkatkan kesejahteraan kehidupan masyarakat, mengingat kualitas lahan yang sebagian kering, rendahnya transfusi IPTEKS, dan budaya hidup masyarakat akan sangat mempengaruhi pada kinerja masyarakat dalam mengentaskan kemiskinan.

Secara sistemik pemberdayaan masyarakat dengan SLA berbasis budaya lokal merupakan suatu upaya inovatif dan prediktif dalam penanganan permasalahan kemiskinan di wilayah lahan kering di kecamatan Nusa Penida, yang tersebar di desa Ped, Kutampi, Tanglad dan desa Batukandik. Model pemberdayaan ini berlandaskan pada upaya pelibatan masyarakat baik secara personal maupun komunal untuk berpartisipasi aktif dalam belajar dan beraksi menanggulangi kemiskinan, dengan tetap bertumpu pada potensi aset wilayah dan budaya lokal masyarakat, sehingga pemberdayaan masyarakat lebih membumi, melibatkan artisipasi aktif warga, dan menyediakan proses pembelajaran dalam membangun budaya belajar dan bekerja di masyarakat. Dengan model pemberdayaan SLA, telah menempatkan KK miskin sebagai subyek pemberdayaan dan agen perubahan dalam menyadari situasi kemiskinannya, merumuskan dan mengimplementasikan program aksi pengentasan kemiskinan.

Penyadaran dan pengkapasitasan masyarakat melalui transfusi ipteks pengolahan limbah teni-ternak menjadi biogas, biofertilizer dan biorganik dalam sistem tani-ternak terintegrasi di tingkat keluarga dan kelompok tani-ternak telah membangun pondasi dasar ketahanan pangan jangka panjang. Di sisi lain, perubahan mindset dan perilaku masyarakat dalam mengembangkan berbasis organik dalam sistem bertani dan beternak telah mendorong proses revitalisasi top-soil permukaan tanah, sehingga dapat mengurangi eskalasi perluasan lahan kering di Nusa Penida. Simpul-simpul aktivitas sosio-ekonomi dengan pendekatan SLA dalam budi daya tani-ternak terpadu bagi masyarakat marginal miskin di kawasan lahan kering di Nusa Penida, ditindak lanjuti dengan program pendampingan dan pelembagaan. Aktivitas ekonomi berbasis tani-ternak diproyeksikan sedemikian rupa, sehingga komunitas marginal memiliki pendapatan (income) yang bersifat harian, bulanan, triwulan, enam bulan, dan tahunan.

Dari parameter waktu kerja produktif, tingkat penghasilan dan kerentanan ketahanan pangan KK miskin maka dapat dikatakan model pemberdayaan masyarakat miskin dengan pendekatan SLA di kawasan lahan kering Nusa Penida telah mampu meningkatkan kualitas hidup masyarakat.

\section{SIMPULAN}

Berdasarkan hasil penelitian ini, maka dapat dikemukakan simpulan sebagai berikut. (1) profil potensi wilayah Nusa Penida di kecamatan Klungkung menunjukkan daya dukung lahan yang cukup luas, dan potensi pertanian-peternakan-perikanan yang cukup tinggi. (2) model pemberdayaan yang secara substansial dan hirakhis berisikan: (i) penyadaran, (ii) pengkapasitasan, (iii) pendampingan, dan pelembagaan. Pemberdayaan masyarakat dalam pengembangan usaha dalam bidang pertanian dalam arti luas, sebagian besar adalah lahan kering. (3) Program aksi pengentasan kemiskinan telah berhasil membangun (1) demplot pengolahan kelapa, demplot pertanian multikultur, dan (2) demplot peternakan berbasis zero waste. (4) model pemberdayaan masyarakat 
miskin dengan the sustainable livelihood approach berbasis budaya lokal secara sistemik memiliki keunggulan dalam program aksi pengentasan kemiskinan di daerah lahan kering Nusa Penida Klungkung-Bali.

Dalam rangka mengoptimalisasi pemberdayaan masyarakat dengan model SLA berbasis budaya lokal sebaiknya dilakukan dengan memanfaatkan mahasiswa KKN dan tenaga alumni Undiksha di kecamatan Nusa Penida dan sekitarnya sebagai katalisator pemberdayaan di kantongkantong kemiskinan untuk mereduksi kesulitan akses masyarakat miskin, dan memberdayakan tokoh masyarakat, sesepuh dan menggala masyarakat dalam mengajak masyarakat untuk aktif dalam program aksi pengentasan kemiskinan.

\section{DAFTAR PUSTAKA}

Badan Pusat Statistik. (2003). Data dan Informai Kemiskinan Tahun 2003. Jakarta.

Dunia. (2009). Pengembangan Model Pemberdayaan Masyarakat dengan Pendekatan PALS bagi Masyarakat Miskin di Kecamatan Gerokgak. Undiksha.
Friedman John. (1992). Empowerment: The Politics of Alternative Development. Blackwell Publishers. Cambridge. USA

Gilbert Alan dan Josef Gugler. (1996). Urbanisasi dan Kemiskinan di Dunia Ketiga. PT Tiara Wacana Yogya. Yogyakarta.

Mc Whirter, E.H. (1991). Empowerement in Councelling. Journal of Counselling and Development 69. 222-7. Dalam Rowlans Jo. 1996. Empowerment Examined Development and Social Diversity, Oxfam, UK, jal 86-92.

Miles, H.B dan Huberman, A.M.(1992). Analisis Data Kualitative. UI Press. Jakarta

Mubyarto. (2000). Membangun Sistem Ekonomi. BPFE. Yogyakarta.

Olivier Serrat. (2008). The Sustainable Livelihoods Approach. Asean Development Bank.

Shadi Hamadeh. (2009). The Sustainable Livelihoods Approach (SLA) in Mena: A Bitter Sweet Experience. Environment and Sustainable Development Unit. Faculty of Agricultural and Food Sciences American University of Beirut.

Sumodiningrat Gunawan. (1999). Pemberdayaan Masyarakat dan JPS. PT. Gramedia. Jakarta. 